\title{
DESENVOLVIMENTO DO SORGO (Sorghum bicolor L. Moench) FORRAGEIRO SUBMETIDO A DIFERENTES TIPOS E DOSES DE ADUBACAO ORGÂNICA.
}

\author{
Renato Américo de Araújo Neto*1; José Teodorico de Araújo Filho; Fernando J. da Silva²; Adolpho Emanuel \\ Quintela Rocha ${ }^{1}$; Joelmir José Albuquerque de Farias ${ }^{1}$
}

\author{
${ }^{1}$ Centro de Ciências Agrárias, Universidade Federal de Alagoas, BR 104 Norte, Km 85, Rio Largo, AL. \\ ${ }^{2}$ Pesquisador da Secretaria de Agricultura, Maceió, AL.
}

*Autor para correspondência: Renato Américo de Araújo Neto, renato.eng.agronomo@hotmail.com.

\begin{abstract}
RESUMO - A cultura do sorgo destaca-se pela sua eficiência em épocas com escassez hídrica, surgindo como forte substituto do milho na alimentação animal. A produção deste está dependente, dentre tantos fatores, da adubação orgânica. Visando isto, este trabalho objetivou estudar o desempenho da cultura do sorgo forrageiro submetido a diferentes fontes e doses de adubo orgânico. $O$ experimento obedeceu ao delineamento inteiramente casualizado, em casa de vegetação, no esquema fatorial, com tratamentos contendo duas fontes de adubos orgânicos (esterco bovino e ovino) e cinco doses de cada adubo (zero; $5 ; 10 ; 15$ e 20 t ha ${ }^{-1}$ ), com quatro repetições. Para avaliação da altura de plantas e área foliar da cultura do sorgo, utilizou-se da equação de Boltzmann, estimando 0 desenvolvimento dos mesmos quando medidos aos 14, 21, 28, 35 e 42 dias após semeadura (DAS). Aos 42 DAS, avaliaram-se estatisticamente as variáveis altura da planta (AP), comprimento e largura da folha +3 e número de folhas (NF). $O$ esterco ovino apresentou melhores rendimentos na AP e NF, havendo interação estatística desses, onde $15 \mathrm{t} \mathrm{ha}^{-1}$ apresentou melhores rendimentos para AP. Quanto ao NF, a testemunha assemelhou-se ao tratamento com maior aplicação de esterco. Quanto à estimativa de crescimento da AP e AF, todos os tratamentos apresentaram ótimos coeficientes de determinação $\left(R^{2}\right)$ para aplicação dos adubos orgânicos.
\end{abstract}

Palavras-chave: agricultura orgânica, esterco bovino, esterco ovino, semi-árido

\section{FORAGE SORGHUM (Sorghum bicolor L. Moench) DEVELOPMENT SUBMITTED TO DIFFERENT TYPES AND LEVELS OF ORGANIC FERTILIZER}

\begin{abstract}
The sorghum crop is distinguished by its efficiency in times with water scarcity, emerging as a strong substitute for corn in animal feed. The production of this depends among many factors the organic fertilization. Aiming at this, this study investigated the performance of the sorghum crop under different sources and levels of organic fertilizer. The experiment followed the completely randomized design in a greenhouse in a factorial with treatments containing two sources of organic manures (cattle and sheep manure) and five doses of each fertilizer (zero , 5, 10,15 and $20 \mathrm{tha}^{-1}$ ) with four replications. For evaluation of plant height and leaf area of sorghum, we used the Boltzmann equation estimating their development when measured at 14, 21, 28, 35 and 42 days after sowing (AS). At 42 DAS, statistically evaluated the variables plant height (PH), leaf length and leaf number (LN). The sheep manure showed better performance in the $\mathrm{PH}$ and $\mathrm{LN}$, no statistical interaction of these, where $15 \mathrm{tha}^{-1}$ showed better yields for $\mathrm{PH}$. As for the $\mathrm{LN}$, the witness was similar to treatment with higher manure application. As for the estimated growth of $\mathrm{PH}$ and LA all treatments showed great determination coefficients $\left(\mathrm{R}^{2}\right)$ for application of organic fertilizers.
\end{abstract}

Keywords: organic agriculture, cattle manure, sheep manure, semi - arid 


\section{INTRODUÇÃO}

A cultura do sorgo (Sorghum bicolor (L.) Moench) vem se destacando na região semiárida do país, principalmente em época de escassez hídrica, surgindo como fonte de substituição ao milho na alimentação animal e ao seu sucesso é garantido devido a grande adaptabilidade e resistência a ambientes com pouca precipitação, sendo cultivado em regiões secas e muito quentes, onde culturas (milho, por exemplo) não atingem o máximo na produtividade de grãos ou forragem (Molina et al., 2000). Plantas $C_{4}$ existem basicamente quatro tipos de sorgo (granifero, forrageiro, vassoura e sacarino), as diferenças são refletidas na posição entre colmos, folhas e panículas, com diferentes produções de matéria seca, composição bromatológica e valor nutritivo (Leite, 2006).

Quinto cereal mais cultivado no mundo, a área cultivada com sorgo no Brasil obteve um significante crescimento, em 1990, era de 140.132 ha, com uma produção de $236.250 \mathrm{t}$, tendo um aumento significativo em 2013 para 731.384 ha e 2.038 .767 t. Na região Nordeste, durante o mesmo período a área plantada aumentou de 18.393 ha para 92.770 ha, comprovando 0 interesse dos produtores locais pela cultura. A escassez de dados referentes desta cultura no estado de Alagoas comprova a necessidade de pesquisa na área de produção e produtividade de massa e grãos (IBGE, 2013).

0 nordeste brasileiro apresenta condições favoráveis para produção da cultura, devido a sua adaptação às baixas e irregulares precipitações pluviométricas. Mesmo assim com todo esse potencial, a produção do sorgo é bastante reduzida, sendo necessário esforço no sentido de difundir e incentivar a produção da mesma, através do incremento em sua produtividade, que depende, dentre outros fatores, da nutrição das plantas (Fernandes et. al., 1991), através da adição de adubos, podendo estes adicionados ao solo em forma química ou orgânica, sendo o último acrescentado, também, na forma de estercos. Este último apresenta diversas vantagens, dentre elas melhoria nas propriedades físicas do solo e melhoramento do fornecimento de nutrientes, aumento no teor de matéria orgânica $e$ consequente aumento na capacidade de troca de cátions (Hoffman, 2001).
O crescimento gradual da adubação orgânica no Brasil, nos últimos anos, se dá principalmente no setor agropecuário, dando origem a vários resíduos orgânicos, fornecendo nutrientes para a produção de alimentos às plantas, melhorando também as condições físicas, químicas e biológicas do solo (Andrade et al., 2011). Verifica-se que a adubação orgânica, utilizando diversos tipos de estercos, proporcionam eficientes rendimentos na produção de milho, tanto para grãos quanto para forragem, onde a decomposição dos adubos orgânicos nos climas tropicais ocorre rapidamente, sendo que uma redução expressiva no seu teor afetará negativamente as funções químicas no solo, resultando na diminuição da produtividade das culturas (Konzen e Alvarenga, 2005). Vários são os trabalhos envolvendo adubação orgânica com diversas culturas, porém, tornando-se escassa quando o plantio é a cultura do sorgo (Freitas et al., 2012; Oliveira et al., 2009; Santos et al., 2009). Diante do exposto e visto a necessidade de estudos referentes à adubação orgânica na cultura do sorgo forrageiro, objetivou-se avaliar o desenvolvimento desta cultura submetido a diferentes tipos e doses de adubação orgânica.

\section{MATERIAL E MÉTODOS}

0 experimento foi conduzido na área experimental do Centro de Ciências Agrárias da Universidade Federal de Alagoas, no município de Rio Largo (9॰28'02" S; 3549'65” W; $127 \mathrm{~m}$ ), localizada nos Tabuleiros Costeiros de Alagoas, no período de março a abril de 2010. 0 experimento foi instalado em vasos, com a variedade de sorgo forrageiro IPA 467.0 delineamento utilizado foi 0 inteiramente casualizado, em esquema fatorial $2 \times 5$, sendo duas fontes de adubo orgânico em forma de esterco (bovino e ovino) e cinco doses de cada fonte de esterco (zero; $5 ; 10 ; 15 ; 20 \mathrm{t} \mathrm{ha}^{-1}$ ), com quatro repetições. Os dados foram submetidos à análise de variância e regressão e as médias comparadas pelo teste de Tukey a $5 \%$ de probabilidade e realizado teste para análise de regressão. Os adubos orgânicos utilizados foram oriundos de uma propriedade particular, localizada na região de Major Izidoro (9³1'57" S; 36059'36" W), na Bacia Leiteira do estado de Alagoas, realizando-se a análise química destes, como mostra na Tabela 1. 
Tabela 1. Atributos químicos do adubo orgânico

\begin{tabular}{c|c|c}
\hline & Esterco Bovino & Esterco Ovino \\
\hline Nitrogênio Total (\%) & 0,32 & 2,21 \\
Fósforo (\%) & 0,14 & 0,46 \\
Potássio (\%) & 0,23 & 1,91 \\
Cálcio (\%) & 0,31 & 2,51 \\
Magnésio (\%) & 0,17 & 0,63 \\
Matéria Orgânica Total (\%) & 31,22 & 67,68 \\
Umidade 100-105 (\%) & 9,05 \\
Ferro (\%) & 2,78 & 0,25 \\
Cobre (\%) & 0,20 & 0,63 \\
Zinco (\%) & 0,17 & $<0,01$ \\
Manganês (\%) & $<0,01$ & 0,02 \\
\hline
\end{tabular}

O solo utilizado foi classificado como Argissolo Vermelho Eutrófico (EMBRAPA, 2006). 0 mesmo foi retirado da Unidade experimental da Secretaria do Estado de Alagoas, localizado na região de Santana do Ipanema (9²2'40" S; 37014'42" W), semi-árido do estado de Alagoas a uma profundidade de $0-20 \mathrm{~cm}$. As análises químicas do solo, de acordo com os métodos descritos por Malavolta et al. (2002), resultaram em: $\mathrm{pH}$ em água $(5,82), \mathrm{P}=10,91 \mathrm{mg} \mathrm{dm}^{-3}, \mathrm{~K}=130 \mathrm{mg} \mathrm{dm}^{-3}$, $\mathrm{Na}=14 \mathrm{mg} \mathrm{dm}^{-3}, \mathrm{Ca}=4,0 \mathrm{cmol}_{\mathrm{c}} \mathrm{dm}^{-3}, \mathrm{Mg}=1,1 \mathrm{cmol}_{\mathrm{c}}$ $\mathrm{dm}^{-3}, \mathrm{Al}=0,05 \mathrm{cmol}_{\mathrm{c}} \mathrm{dm}^{-3}, \mathrm{H}+\mathrm{Al}=3,47 \mathrm{cmol}_{\mathrm{c}} \mathrm{dm}^{-3}, \mathrm{SB}$ $=5,49 \mathrm{cmol}_{\mathrm{c}} \mathrm{dm}^{-3}, \mathrm{CTC}=8,96 \mathrm{cmol}_{\mathrm{c}} \mathrm{dm}^{-3}, \mathrm{~V}=61,32 \%$ e $m=0,55 \%$.

Após secagem do solo, o mesmo foi peneirado e acondicionado em vasos de polietileno de $10 \mathrm{~kg} \mathrm{e}$ misturados aos tratamentos contendo tipos e doses de adubos orgânicos, realizando-se o semeio de oito sementes de sorgo forrageiro, desbastando as plantas com baixo desenvolvimento, deixando três plantas por vaso. Para o suprimento hídrico das plantas, adotouse que todos os vasos seriam condicionados a uma lâmina hídrica correspondendo à capacidade de campo do vaso, evitando estresse hídrico pelas plantas.

Para a avaliação de crescimento da cultura do sorgo foram feitas medidas aos 14, 21, 28, 35 e 42 dias após semeadura (DAS), realizando-se as seguintes variáveis: altura da planta (AP), comprimento e largura (folha +3), área foliar (AF) e número de folhas (NF). Aárea foliar de cada planta foi baseada nas medidas biométricas e no cálculo realizado de acordo com a relação proposta por Hermann \& Camara (1999), como segue:

$$
A F=(0,75 . \mathrm{C} \cdot \mathrm{L}) .(\mathrm{N} . \mathrm{F}+2)
$$

onde: C e L são comprimento e largura da folha +3; NF é o número de folhas expandidas com área verde maior que $20 \%$ e 0,75 é um fator de correção.

A variação da área foliar e altura da planta no ciclo da cultura foram obtidas pela equação de Boltzmann, onde foi ajustada para as observações da AF e AP dos tratamentos utilizados com esterco bovino e ovino, em função dos dias após semeadura (DAS), como segue:

$Y=\frac{-a}{1+\exp (x-b) / c}+a$

em que: Y é a AF ou AP, "a" é o AF ou AP máximo, " $x$ " é o DAS, "b" é o valor central do DAS e "c" é a faixa do DAS onde os valores de AF ou AP mudam. Os valores dos coeficientes foram submetidos ao teste de Tukey aos níveis de 1 e $5 \%$ de probabilidade.

\section{RESULTADOS E DISCUSSÃO}

A Tabela 2 apresenta as médias para os adubos orgânicos para as variáveis altura de plantas, comprimento e largura da folha "+3" e número de folhas. Observa-se que, de acordo com o teste Tukey, a variável altura de plantas apresentou significância a $5 \%$, onde a média para o esterco ovino apresentou melhor resultado quando comparado com o esterco bovino. Resultado semelhante foi observado para a variável número de folhas, que diferiu estatisticamente a $1 \%$ de probabilidade. Provavelmente essa superioridade na altura de planta e número de folha, deve-se à maior concentração de nutrientes contidos no esterco ovino (Tabela 1). A aplicação dos estercos bovino e ovino não apresentaram diferenças para as variáveis comprimento da folha e largura da folha. Houve ainda 
significância para interação doses $x$ tipos de adubos para a variável altura de plantas $(5 \%)$ e número de folhas (1\%). Resultados diferentes foram observados por Freitas et al. (2012), que trabalhando com esterco bovino, constatou semelhança nas variáveis altura de plantas e número de folhas até uma dosagem de $60 \mathrm{t}$ ha ${ }^{-1}$ de adubo orgânico.

Tabela 2. Médias para os adubos orgânicos para Altura de Plantas, comprimento e largura da folha "+3" e número de folhas

\begin{tabular}{ccccc}
\hline & $\begin{array}{c}\text { Altura } \\
(\mathrm{cm})\end{array}$ & $\begin{array}{c}\text { Comprimento } \\
(\mathrm{cm})\end{array}$ & $\begin{array}{c}\text { Largura } \\
(\mathrm{cm})\end{array}$ & Número de folhas \\
\hline Bovino (B) & $107,29 \mathrm{~b}$ & $74,33 \mathrm{a}$ & $2,91 \mathrm{a}$ & $5,00 \mathrm{~b}$ \\
Ovino (O) & $113,89 \mathrm{a}$ & $78,48 \mathrm{a}$ & $3,09 \mathrm{a}$ & $6,00 \mathrm{a}$ \\
\hline CV\% & 9,17 & 8,44 & 12,46 & 7,90 \\
F & $4,23^{*}$ & $4,12 \mathrm{~ns}$ & $2,24 \mathrm{~ns}$ & $11,21^{* *}$ \\
F Interação BxO & $2,51^{*}$ & $2,34 \mathrm{~ns}$ & $0,80 \mathrm{~ns}$ & $1,36^{* *}$ \\
\hline
\end{tabular}

${ }^{* *}$ - signicativo a $1 \%$ pelo teste de Tukey; ${ }^{*}$ - significativo a $5 \%$; ns - não significativo. Médias seguidas das mesmas letras na mesma coluna não diferem estatisticamente pelo teste de Tukey

A interação entre tipos e doses de adubos orgânicos para a variável altura da planta e número de folhas são apresentadas na Tabela 3. Observa-se que a aplicação de 15 toneladas por hectare ( $\left.\mathrm{tha}^{-1}\right)$ de esterco ovino apresentou melhor resultado quando comparado à mesma proporção de esterco bovino. Apesar dos demais resultados não apresentarem diferenças estatísticas, observa-se que a aplicação de 10 e 20 t ha $^{-1}$ de esterco ovino proporcionaram maiores incrementos na altura de plantas. Já para a variável número de folhas, a interação mostra que a aplicação de $20 \mathrm{t} \mathrm{ha}^{-1}$ do esterco ovino proporcionou melhores resultados para esta variável. Observa-se ainda que tanto a aplicação de $20 \mathrm{t} \mathrm{ha}^{-1}$, quanto a não aplicação de esterco ovino, proporcionaram rendimentos semelhantes, com produção de 6 folhas na planta. Oliveira et al. (2009), ao estudarem o desenvolvimento da mamoneira constataram a não significância da variável altura das plantas quando submetidas à esterco bovino e ovino. Essa diferença pode ser ocasionada devido ao metabolismo das diferentes plantas e a consequente absorção dos nutrientes essenciais para as mesmas.

Tabela 3. Interação entre tipos de adubos e doses destes para altura da planta.

\begin{tabular}{|c|c|c|c|c|c|}
\hline \multicolumn{6}{|c|}{ Altura da Planta } \\
\hline \multirow{2}{*}{ Tipos de adubos } & \multicolumn{5}{|c|}{ Doses } \\
\hline & Zero t ha-1 $^{-1}$ & $5 \mathrm{t} \mathrm{ha}^{-1}$ & $10 \mathrm{t} \mathrm{ha}^{-1}$ & $15 \mathrm{t} \mathrm{ha}^{-1}$ & $20 \mathrm{t} \mathrm{ha}^{-1}$ \\
\hline Bovino & 109,95 a & $110,60 \mathrm{a}$ & 107,97 a & $95,12 \mathrm{~b}$ & $112,81 \mathrm{a}$ \\
\hline Ovino & \multicolumn{5}{|c|}{ Número de Folhas } \\
\hline \multirow{2}{*}{ Tipos de adubos } & \multicolumn{5}{|c|}{ Doses } \\
\hline & Zero t ha-1 $^{-1}$ & $5 \mathrm{t} \mathrm{ha}^{-1}$ & 10 t ha $^{-1}$ & $15 \mathrm{t} \mathrm{ha}^{-1}$ & $20 \mathrm{t} \mathrm{ha}^{-1}$ \\
\hline Bovino & $5,00 \mathrm{~b}$ & $5,00 \mathrm{a}$ & $5,00 \mathrm{a}$ & $5,00 a$ & $5,00 \mathrm{~b}$ \\
\hline Ovino & $6,00 \mathrm{a}$ & $5,00 \mathrm{a}$ & $5,00 \mathrm{a}$ & $5,00 \mathrm{a}$ & $6,00 \mathrm{a}$ \\
\hline
\end{tabular}

Médias seguidas das mesmas letras na mesma coluna não diferem estatisticamente pelo teste de Tukey

Quanto à análise de regressão, apenas 0 esterco ovino apresentou coeficientes significativos, sendo apresentados na Figura 1. Observa-se que para a variável altura da planta, o melhor ajuste ao modelo matemático foi a do tipo quadrática, tendo um decréscimo iniciado quando adicionou ao solo $10 \mathrm{t} \mathrm{ha}^{-1}$ de esterco ovino, com um coeficiente de correlação considerado forte (Figura 1A). Calculando a primeira 
derivada desta equação, observa uma máxima eficiência econômica de 20,75 $\mathrm{tha}^{-1}$, indicando que a dosagem de $20 \mathrm{t}^{-1} \mathrm{a}^{-1}$ tende a quantidade mínima a ser aplicada quando utilizar-se a adubação orgânica com esterco ovino, para o desenvolvimento em altura das plantas de sorgo. Avaliando-se as variáveis comprimento da folha e largura da folha (Figura 1B e 1C), observa-se uma regressão linear em relação ao aumento das doses de esterco ovino. Os coeficientes de correlação apresentaram-se moderado para comprimento da folha e forte para largura da folha. Observa-se que o efeito da adubação orgânica sobre 0 desenvolvimento das plantas de sorgo se devem à condições diretas (melhoria da estrutura e fertilidade do solo) e indiretas (capacidade de retenção de água), proporcionando aproveitamento dos nutrientes existentes no solo, onde, o suplemento desses nutrientes de forma equilibrada, colaboram para 0 melhor desenvolvimento da cultura (Peavy e Greig, 1972; Andrade Neto, et al. 2010).

Figura 1. Regressão polinomial para as variáveis Altura da planta (A), Comprimento da folha (B) e Largura da folha $(C)$ para diferentes doses de esterco ovino, para a cultura do sorgo forrageiro
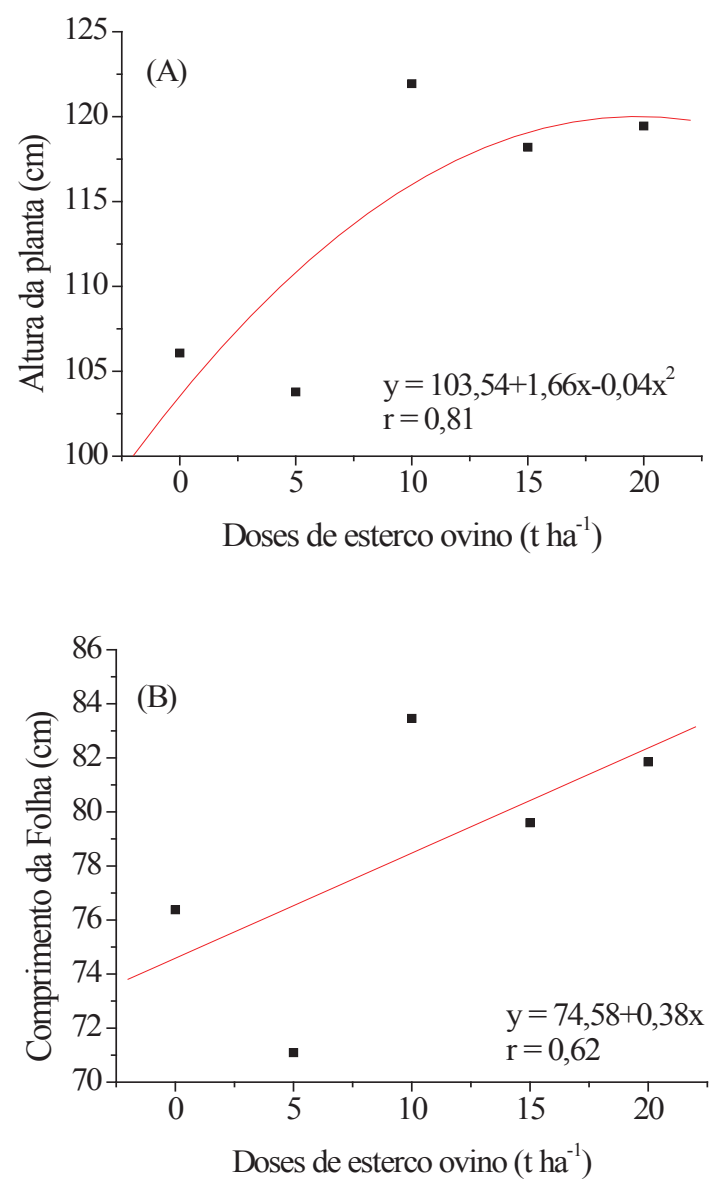

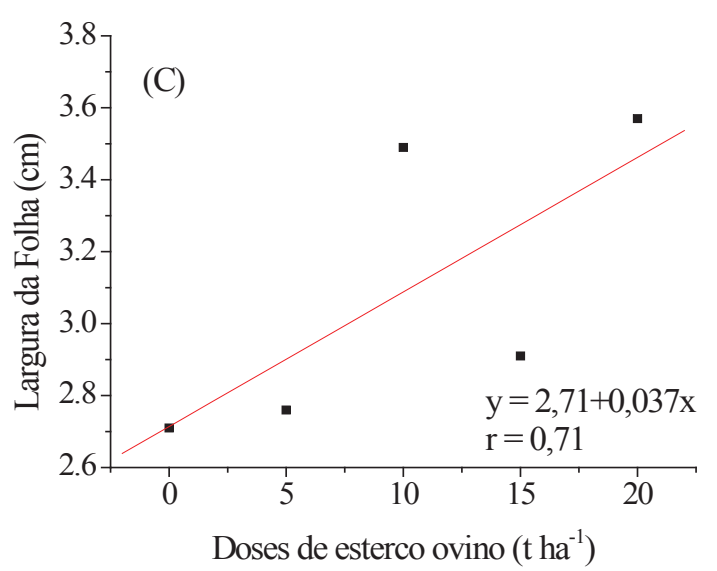

As curvas de crescimento medidas e estimadas pela equação de Boltzmann e os parâmetros desta equação, para altura da planta quando aplicados diferentes doses de esterco bovino, são apresentados na Figura 2 e Tabela 4. Observa-se uma tendência de semelhante crescimento ao longo dos dias após a semeadura (DAS), para todas as doses aplicadas (Figura 2). A testemunha apresentou uma altura final de 109,95 $\mathrm{cm}$, enquanto as diferentes doses apresentaram uma variação de 95,13 (Figura 2D) a 112,81 $\mathrm{cm}$ (Figura 2E). Os valores estimados (linha vermelha) aproximaram-se daqueles medidos durante o experimento para todos os tratamentos estudados.

Os parâmetros apresentaram um excelente ajuste quando os valores foram estimados por Boltzmann. Os parâmetros "a", "b" e "c" para a testemunha (zero t ha-1) foram significativos a $1 \%$ pelo teste de Tukey, podendo ser utilizados para determinação da altura diária para a cultura do sorgo forrageiro, variedade IPA467. O parâmetro "c" para os demais tratamentos apresentaram significância a $5 \%$ de probabilidade e também podem ser aplicados para determinação da altura diária ao longo do cultivo, para as diferentes doses de esterco bovino aplicado. Araújo Neto (2013), avaliando o crescimento da canade-açúcar, através da equação de Boltzman, observou semelhança nos parâmetros estatísticos, podendo utilizar-se esse modelo para crescimento gramíneas monocotiledôneas, como milho, sorgo e cana-de-açúcar. 
Figura 2. Variação da Altura da planta em função dos dias após semeadura para um cultivo de sorgo forrageiro adubado com esterco Bovino, em Rio Largo, Alagoas. (a) zero t ha-1; (b) $5 \mathrm{t} \mathrm{ha}^{-1}$; (c) $10 \mathrm{t} \mathrm{ha}^{-1}$; (d) $15 \mathrm{t} \mathrm{ha}^{-1}$; (e) 20 t ha $^{-1}$

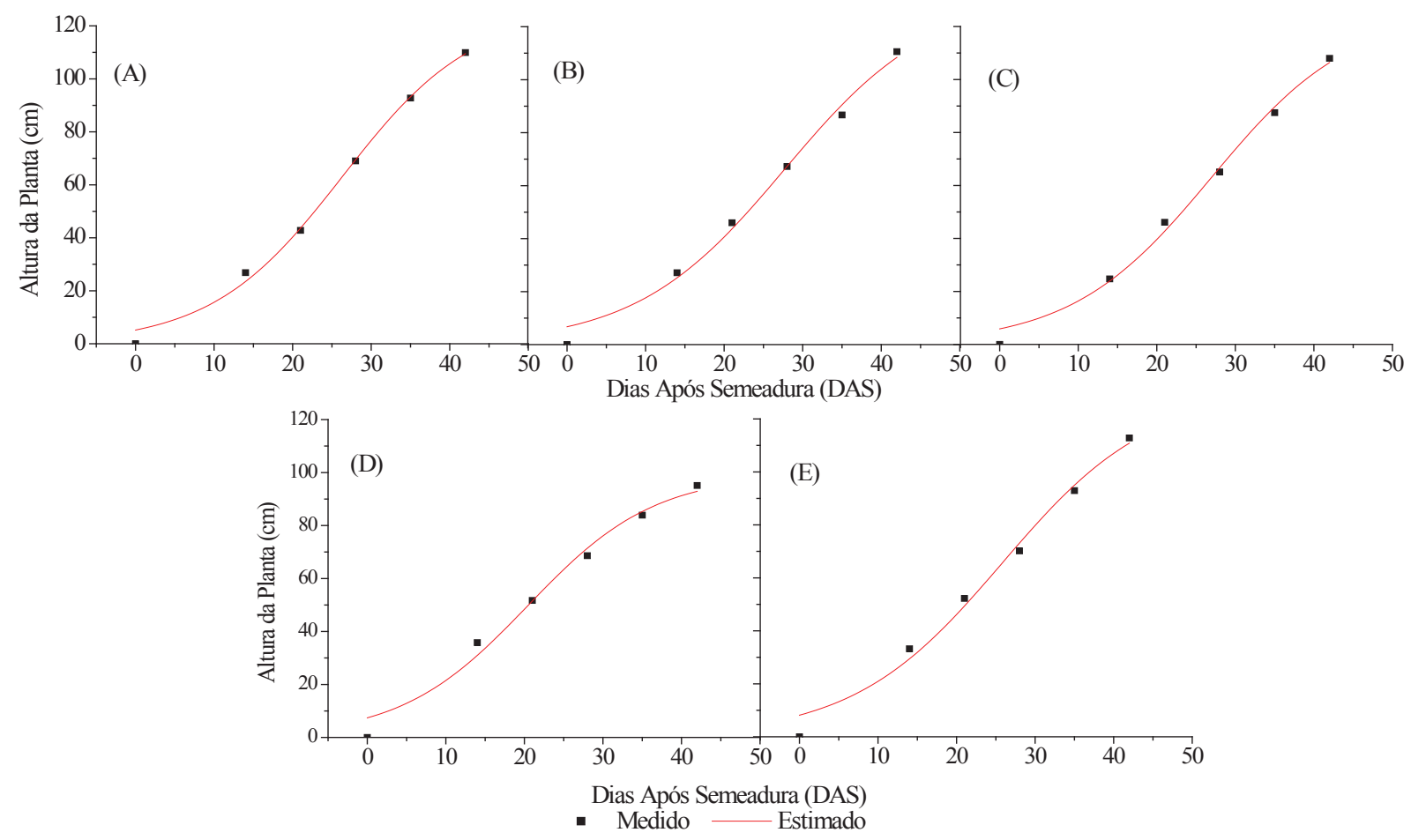

Tabela 4. Parâmetros da equação de Boltzmann para Altura de plantas quando adicionado Adubo Bovino.

\begin{tabular}{cccccc}
\hline \multirow{2}{*}{ Parâmetros } & \multicolumn{5}{c}{ Doses } \\
\cline { 2 - 6 } & Zero tha- $^{-1}$ & 5 t ha $^{-1}$ & 10 t ha $^{-1}$ & 15 t ha- $^{-1}$ & 20 tha $^{-1}$ \\
\hline a & $126,35 \pm 10,34^{* *}$ & $132,30 \pm 18,99^{* *}$ & $126,21 \pm 14,39^{* *}$ & $99,36 \pm 9,43^{* *}$ & $131,00 \pm 19,33^{* *}$ \\
b & $26,35 \pm 1,83^{* *}$ & $27,69 \pm 3,42^{* *}$ & $26,98 \pm 2,64^{* *}$ & $20,41 \pm 2,27^{* *}$ & $25,78 \pm 3,62^{* *}$ \\
c & $8,36 \pm 1,14^{* *}$ & $9,45 \pm 1,87^{*}$ & $8,93 \pm 1,54^{*}$ & $8,09 \pm 1,90^{*}$ & $9,51 \pm 2,17^{*}$ \\
\hline$R^{2}$ & 0,99 & 0,99 & 0,99 & 0,98 & 0,98 \\
\hline
\end{tabular}

${ }^{* *}$ - signicativo a $1 \%$ pelo teste de Tukey; ${ }^{*}$ - significativo a $5 \%$

A variação da área foliar da planta medidos e estimados pela equação de Boltzmann, bem como os parâmetros ajustados por esta equação para a variável área foliar, em diferentes dosagens de esterco bovino é apresentada na Figura 3 e Tabela 5. Observa-se excelente ajuste nos dados comparados com os dados estimados, em que o maior valor da área foliar foi observado quando aplicou-se $20 \mathrm{t} \mathrm{ha}^{-1}$ (Figura 3E) de esterco bovino ao solo. Essa dose correspondeu a um incremento de $192.83 \mathrm{~cm}^{2}$ de área foliar, 28,6\% acima que o menor valor observado (Figura 3C). A testemunha (Figura 3A) correspondeu a $88 \%$ do maior valor observado. Observa-se que há um excelente ajuste desses parâmetros (Tabela 5 ), indicando que estes podem ser utilizados para cálculo da área foliar diária. Para a testemunha (sem aplicação de esterco), observa-se uma taxa de crescimento inicial de $0,13 \mathrm{~cm}^{2} \mathrm{dia}^{-1}$, com pico de crescimento de $5,92 \mathrm{~cm}^{2} \mathrm{dia}^{-1}$, aos 31 DAS. Durante esse mesmo DAS, para $20 \mathrm{t} \mathrm{ha}^{-1}$, observa-se uma taxa de crescimento de $5,94 \mathrm{~cm}^{2} \mathrm{dia}^{-1}$. Porém, o pico de crescimento para esse tratamento foi aos 34 DAS, com 6,12 $\mathrm{cm}^{2} \mathrm{dia}^{-1}$ (Figura 3A e 3E; Tabela 5). Os parâmetros "a", "b" e "c" foram significativos a $1 \%$ de probabilidade para testemunha (zero t ha-1 $\left.{ }^{-1}\right), 15$ e 20 t ha-1. 0 parâmetro "a" foi significativo a $5 \%$ para os tratamentos 5 e $10 \mathrm{t} \mathrm{ha}^{-1}$. Todos os ajustes podem ser utilizados com eficiência para cálculo da área foliar do sorgo forrageiro, para as diferentes doses de esterco bovino. 
Figura 3.Variação da Área Foliar da planta em função dos dias após semeadura para um cultivo de sorgo forrageiro adubado com esterco Bovino, em Rio Largo, Alagoas. (a) zero t ha- ${ }^{-1}$; (b) 5 t ha- $^{-1}$; (c) $10 \mathrm{t} \mathrm{ha}^{-1}$; (d) $15 \mathrm{t} \mathrm{ha}^{-1}$; (e) 20 t ha $a^{-1}$.

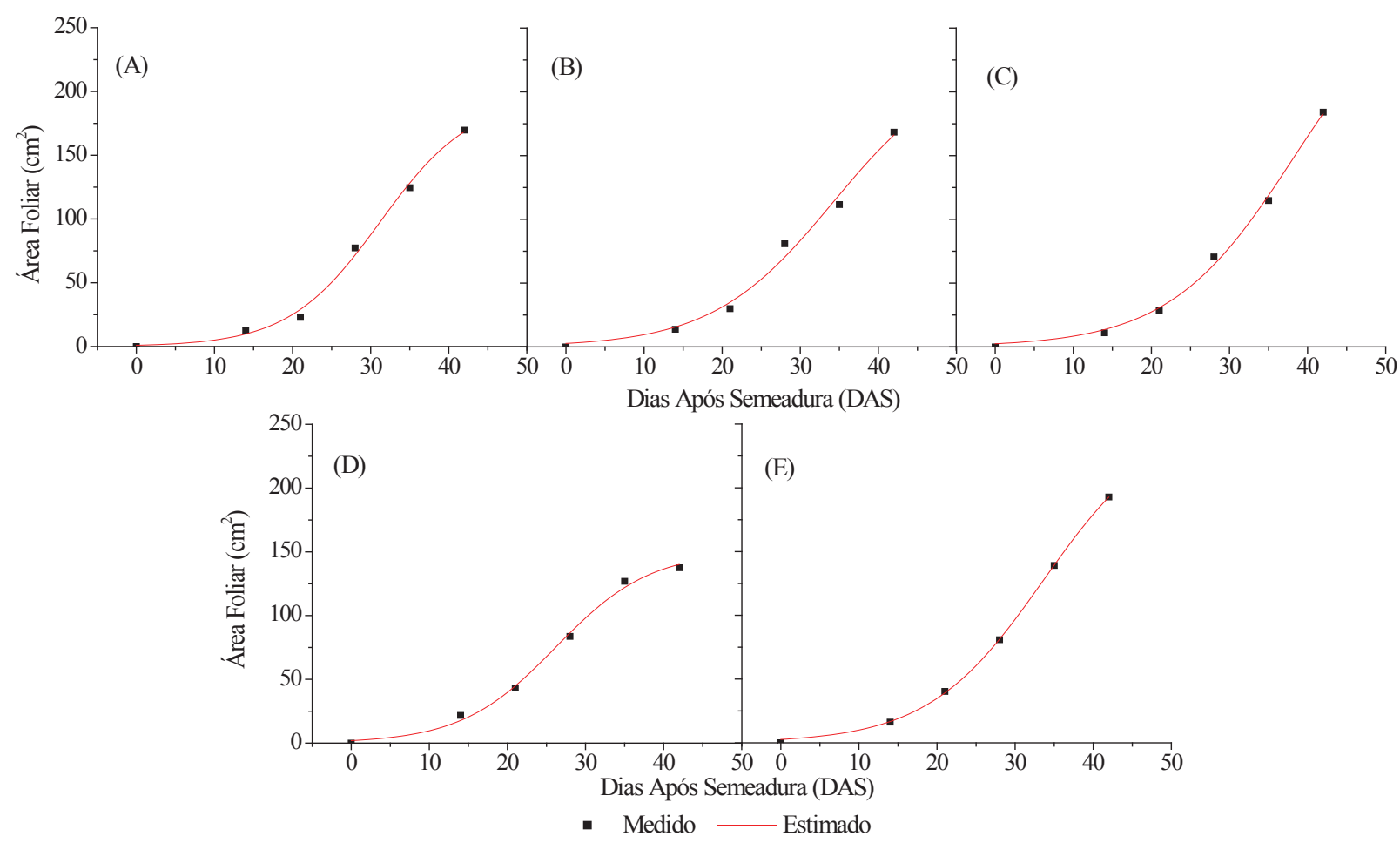

Tabela 5. Parâmetros da equação de Boltzmann para Área Foliar de plantas quando adicionado Adubo Bovino.

\begin{tabular}{cccccc}
\hline \multirow{2}{*}{ Parâmetros } & \multicolumn{5}{c}{ Doses } \\
\cline { 2 - 6 } & Zero tha- $^{-1}$ & 5 t ha $^{-1}$ & 10 tha $^{-1}$ & 15 t ha $^{-1}$ & 20 t ha $^{-1}$ \\
\hline a & $195,05 \pm 16,46^{* *}$ & $226,79 \pm 52,89^{*}$ & $298,57 \pm 59,22^{*}$ & $150,44 \pm 8,03^{* *}$ & $254,31 \pm 9,42^{* *}$ \\
b & $31,18 \pm 1,39^{* *}$ & $34,19 \pm 4,31^{* *}$ & $38,31 \pm 3,40^{* *}$ & $26,18 \pm 1,01^{* *}$ & $33,58 \pm 0,67^{* *}$ \\
c & $5,85 \pm 0,80^{* *}$ & $7,75 \pm 1,79^{*}$ & $7,99 \pm 1,06^{* *}$ & $6,05 \pm 0,73^{* *}$ & $7,38 \pm 0,29^{* *}$ \\
\hline$R^{2}$ & 0,99 & 0,99 & 0,99 & 0,99 & 0,99 \\
\hline
\end{tabular}

** - signicativo a $1 \%$ pelo teste de Tukey; ${ }^{*}$ - significativo a $5 \%$

A Figura 4 apresenta a altura da planta medida e estimada pela equação de Boltzmann para a cultura do sorgo forrageiro. Observa-se uma proximidade nos valores medidos quando adicionados ao solo a quantidade de 10,15 e 20 tha $^{-1}$ de esterco ovino (Figura 4C, 4D e 4E), variando de 121,94 cm (Figura 4C) a 118,21 cm (Figura 4D). Estes foram maiores que a testemunha (Figura 4A) em 14,95; 11,43 e 12,61\% para 10 t ha $^{-1}, 15$ t ha $^{-1}$ e 20 t ha $^{-1}$, respectivamente.

A Tabela 6 apresenta os parâmetros de crescimento estimados pela equação de Boltzmann para as cinco doses de esterco ovino. Observa-se que apenas 0 tratamento $5 \mathrm{t} \mathrm{ha}^{-1}$ apresentou todos os parâmetros significativos a $1 \%$ e que os demais apresentaram o parâmetro "c" significativo a 5\%. Temse um excelente ajuste para todos os tratamentos com coeficiente de determinação de 0,99 (exceto para 20 $t$ ha $^{-1}$ ), indicando que estes podem ser utilizados para estimativa de crescimento da planta em período diário.

A Figura 5 apresenta 0 crescimento da área foliar para os cinco tratamentos estudados, em função dos dias após a semeadura, medidos e estimados pela equação de Boltzmann. Observa-se que as dosagens de 10 e 20 t ha $^{-1}$ apresentaram melhores áreas foliares durante o período de desenvolvimento da parte aérea do sorgo, com médias finais de 226,65 e 226,79 $\mathrm{cm}^{2}$, respectivamente para 10 e $20 \mathrm{t} \mathrm{ha}^{-1}$ (Figura 5C e $5 \mathrm{E}$ ). 0 menor valor foi observado quando a cultura 
foi submetida a $5 \mathrm{t} \mathrm{ha}^{-1}$ de esterco ovino (Figura $5 \mathrm{~B}$ ), relação às curvas de crescimento, tem-se que todas as $4,42 \%$ inferior que a testemunha, comprovando a mensurações feitas para a dosagem de 20 tha $^{-1}$ foram $^{2}$ ineficácia dessa dosagem para o sorgo forrageiro. Em superior aos demais tratamentos (Figura 5E).

Figura 4. Variação da Altura da planta em função dos dias após semeadura para um cultivo de sorgo forrageiro adubado com esterco Ovino, em Rio Largo, Alagoas. (a) zero t ha-1; (b) $5 \mathrm{t} \mathrm{ha}^{-1}$; (c) $10 \mathrm{t} \mathrm{ha}^{-1}$; (d) $15 \mathrm{t} \mathrm{ha}^{-1}$; (e) $20 \mathrm{t}$ ha $^{-1}$.

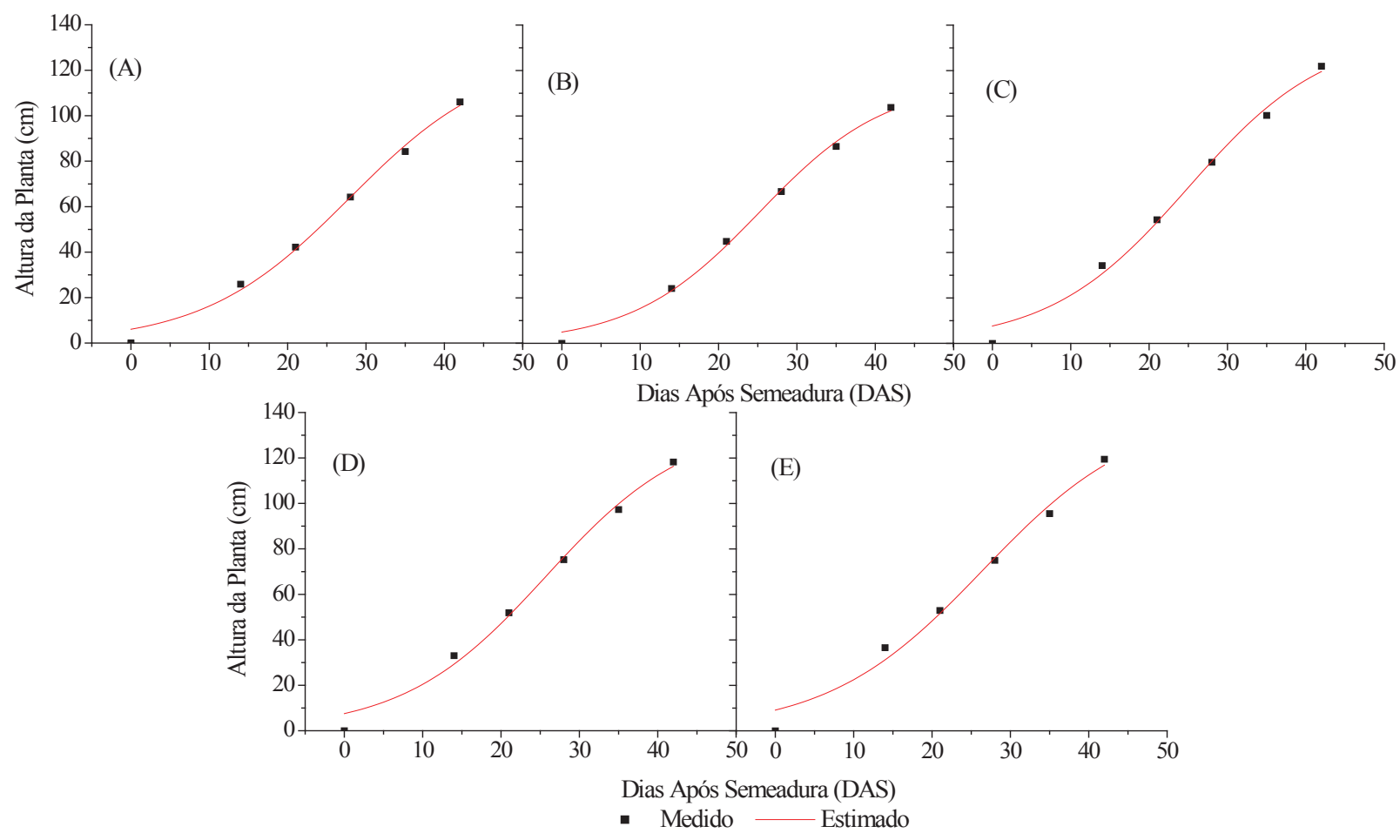

Tabela 6. Parâmetros da equação de Boltzmann para Altura de plantas quando adicionado Adubo Ovino

\begin{tabular}{cccccc}
\hline \multirow{2}{*}{ Parâmetros } & \multicolumn{5}{c}{ Doses } \\
\cline { 2 - 6 } & Zero tha- $^{-1}$ & 5 tha $^{-1}$ & 10 t ha $^{-1}$ & 15 t ha $^{-1}$ & 20 t ha $^{-1}$ \\
\hline a & $127,47 \pm 16,20^{* *}$ & $115,20 \pm 8,53^{* *}$ & $136,97 \pm 14,91^{* *}$ & $135,67 \pm 15,97^{* *}$ & $141,26 \pm 24,53^{* *}$ \\
b & $27,88 \pm 2,99^{* *}$ & $25,19 \pm 1,66^{* *}$ & $24,97 \pm 2,57^{* *}$ & $25,71 \pm 2,80^{* *}$ & $26,47 \pm 4,34^{* *}$ \\
c & $9,30 \pm 1,63^{*}$ & $8,11 \pm 1,11^{* *}$ & $8,82 \pm 1,67^{*}$ & $9,07 \pm 1,73^{*}$ & $9,90 \pm 2,47^{*}$ \\
\hline$R^{2}$ & 0,99 & 0,99 & 0,99 & 0,99 & 0,98 \\
\hline
\end{tabular}

** - signicativo a $1 \%$ pelo teste de Tukey; ${ }^{*}$ - significativo a $5 \%$ 
Figura 5. Variação da Área Foliar da planta em função dos dias após semeadura para um cultivo de sorgo forrageiro adubado com esterco Ovino, em Rio Largo, Alagoas. (a) zero tha ${ }^{-1}$; (b) $5 \mathrm{t} \mathrm{ha}^{-1}$; (c) $10 \mathrm{t} \mathrm{ha}^{-1}$; (d) $15 \mathrm{t} \mathrm{ha}^{-1}$; (e) 20 tha $^{-1}$.

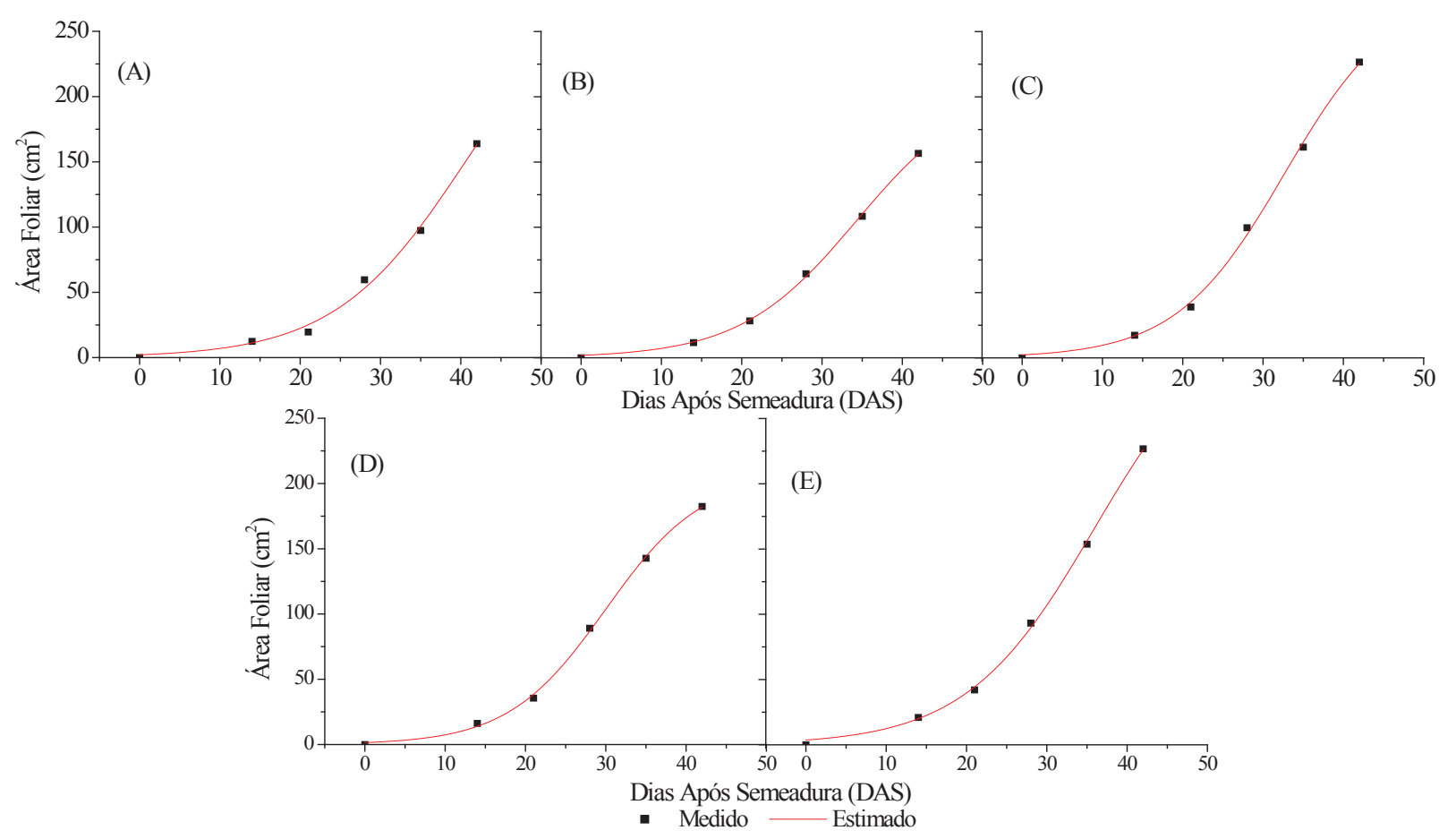

A Tabela 7 apresenta os parâmetros de crescimento estimados pela equação de Boltzmann para as cinco doses de esterco ovino, em relação à área foliar da folha. Observa-se que não houve significância para o parâmetro "a" na testemunha (zero t ha-1). Para o mesmo tratamento, o parâmetro "c" apresentou uma significância de $5 \%$ quando avaliada estatisticamente pelo teste de Tukey, enquanto o parâmetro "b" apresentou nível significativo de $1 \%$. Os demais tratamentos apresentaram uma significância de $1 \%$ no teste de Tukey, podendo ser utilizados para estimativa de crescimento da área foliar, em relação às dosagens aplicadas.

Os diferentes tipos e doses de adubos orgânicos afetaram diferenciadamente 0 desenvolvimento do sorgo forrageiro na altura da planta e número de folhas, onde $15 \mathrm{tha}^{-1}$ de esterco ovino apresentou melhores índices na altura das plantas. Quanto à estimativa de crescimento da AP e $A F$, todos os tratamentos apresentaram ótimos coeficientes de determinação $\left(R^{2}\right)$ para aplicação dos adubos orgânicos. Há necessidade de estudos com maiores dosagens de esterco, com finalidade de estimar a melhor dose eficiente desse produto.

Tabela 7. Parâmetros da equação de Boltzmann para Área Foliar de plantas quando adicionado Adubo Ovino

\begin{tabular}{cccccc}
\hline \multirow{2}{*}{ Parâmetros } & \multicolumn{5}{c}{ Doses } \\
\cline { 2 - 5 } & Zero t ha- & 5 t ha- $^{-1}$ & 10 t ha $^{-1}$ & 15 tha $^{-1}$ & 20 t ha $^{-1}$ \\
\hline A & $302,52 \pm 103,43 \mathrm{~ns}$ & $210,70 \pm 12,26^{* *}$ & $282,00 \pm 20,12^{* *}$ & $207,11 \pm 7,33^{* *}$ & $332,23 \pm 30,20^{* *}$ \\
B & $40,70 \pm 5,63^{* *}$ & $34,34 \pm 1,02^{* *}$ & $32,68 \pm 1,24^{* *}$ & $29,97 \pm 0,61^{* *}$ & $35,95 \pm 1,65^{* *}$ \\
C & $8,20 \pm 1,48^{*}$ & $7,28 \pm 0,43^{* *}$ & $6,78 \pm 0,60^{* *}$ & $6,07 \pm 0,37^{* *}$ & $7,99 \pm 0,60^{* *}$ \\
\hline$R^{2}$ & 0,99 & 0,99 & 0,99 & 0,99 & 0,99 \\
\hline
\end{tabular}

** - signicativo a $1 \%$ pelo teste de Tukey; ${ }^{*}$ - significativo a 5\%; ns - não significativo 


\section{REFERÊNCIAS BIBLIOGRÁFICAS}

ANDRADE, A. R. S.; MACHADO, C. B.; VILELA, E. L.; CAMÊLO, D. L.; SILVA, L. C. C. Desenvolvimento da cultura do sorgo em um latossolo amarelo submetido à adubação orgânica. Revista Brasileira. de Tecnologia Aplicada nas Ciências Agrárias, 2011, 4, 2, 137-151.

ANDRADE NETO, R. C.; MIRANDA, N. O.; DUDA, G. P.; GÓES, G. B.; LIMA, A. S. Crescimento e produtividade do sorgo forrageiro BR 601 sob adubação verde. Revista Brasileira de Engenharia Agrícola e Ambiental, 2010, 14, 2, 124-130.

ARAÚJO NETO, R. A. Métodos para determinar evapotranspiração real da cana-de-açúcar. 2013. 79f. Dissertação (Mestrado em Agronomia: Produção Vegetal) - Centro de Ciências Agrárias, Universidade Federal de Alagoas, Rio Largo, 2013.

EMBRAPA. Centro Nacional de Pesquisa de Solos. Sistema Brasileiro de classificação de solos / [editores técnicos, Humberto Gonçalves dos Santos... et al.] 2.ed. - Rio de Janeiro: Embrapa Solos, 2006. 306p.

FERNANDES, V. L. B.; NUNES, L. A. P.; FILHO, M. M.; SOUZA, V. L.; FERNANDES, M. B. Absorção e utilização de nitrogênio em planta de sorgo cultivado em solução nutritiva. Revista Ciência Agronômica, 1991, 22, 89-96.

FREITAS, G. A.; SOUSA, C. R.; CAPONE, A.;AFFÉRRI, F. S.; MELO, A. V.; SILVA, R. R. Adubação orgânica no sulco de plantio e sua insuficiência no desenvolvimento do sorgo. Journal of Biotechnology and Biodiversity, 2012, 3, 1, 61-67.

HERMANN, E. R.; CÂMARA, G. M. S. Um método simples para estimar a área foliar de cana-de-açúcar. STAB, 1999, 17, 5, 32-34.

HOFFMANN, I.; GERLING, D.; KYIOGWOM, U.B.; MANÉ-BIELFELDT, A. Farmers management strategies to maintain soil fertility in a remote area in northwest Nigeria. Agriculture, Ecosystem Environmental, 2001, 86, 263-275.
IBGE - FUNDAÇÃO INSTITUTO BRASILEIRO DE GEOGRAFIA E ESTATÍSTICAS. Sistema IBGE de Recuperação Automática, 2013. Disponível em <http:// www.sidra.ibge.gov.br/>. Acesso em: 17 de jan. 2013.

KONZEN, E.A.; ALVARENGA, R.A. Manejo e Utilização de Dejetos Animais: aspectos agronômicos e ambientais. Ministério da Agricultura, Pecuária e Abastecimento. Sete Lagoas: Circular Técnica 63, 2005. 65 p. (Circular Técnica, 63).

LEITE, M.L.M.V. Crescimento vegetativo do sorgo sudão (Sorghum sudanense(piper) stapf), em função da disponibilidade de água e fontes de fósforo. 2006. $85 f$. Dissertação (Mestrado em Zootecnia) - Universidade Federal da Paraíba, Areia, 2006.

MALAVOLTA, E.; PIMENTEL-GOMES, F.; ALCARDE, J.C. Adubos e adubações. São Paulo: Nobel, 2002. 200p.

MOLINA, L. R.; GONÇALVES, L. C.; RODRIGUEZ, N. M.; RODRIGUES, J. A. S.; FERREIRA, J. J.; FERREIRA, V. C. P., Avaliação agronômica de seis híbridos de sorgo (Sorghum bicolor (L.) Moench). Arquivo Brasileiro de Medicina Veterinária e Zootecnia, 2000, 52, 385-390.

OLIVEIRA, F. A.; OLIVEIRA FILHO, A. F.; MEDEIROS, J. F.; ALMEIDA JUNIOR, A. B.; LINHARES, P. C. Desenvolvimento inicial da mamoneira sob diferentes fontes e doses de matéria orgânica. Revista Caatinga, 2009, 22, 1, 206-211.

PEAVY, W.S.E.; GREIG, J.K. Organic and mineral fertilizers compared by yield, quality and composition of spinach. Journal of American Society for Horticultural Science, 1972, 97, 718 -723.

SANTOS, J. F.; GRANGEIRO, J. I. T.; OLIVEIRA, M. E. C.; BEZERRA, S. A.; SANTOS, M. C. C. A. Adubação orgânica na cultura do milho no brejo paraibano. Engenharia Ambiental, 2009, 6, 2, 209-216. 